\title{
A cena da leitura nas memórias de infância
}

\author{
Myriam Ávila \\ Universidade Federal de Minas Gerais
}

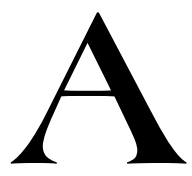

narrativa dos livros de memórias apresenta, ao abordar a infância do memorialista, uma série de características comuns que podem ser vistas como formando um topos: o topos da infância. Esse topos é de tal forma codificado que faz o restante da experiência lembrada, juventude, maturidade, velhice, parecer completamente destacada, - em termos de representação, de estrutura, de estilo, enfim, da narrativa da chamada "primeira quadra" da vida. O relato da infância costuma se distanciar tanto das demais lembranças que vários autores preferiram dedicar-lhe um volume separado, quando não resumiram suas memórias a apenas esse período. É o caso de dois autores de que se tratará aqui: Graciliano Ramos e José Lins do Rego.

O peso do topos, ou seja, de todo um encadeamento semântico evocado pela palavra infância, impregna o narrativa de exemplaridade. Principalmente a associação com as idéias de autenticidade e sinceridade sugerem que o relato desse período fornece os traços do verdadeiro eu, aquele ao qual, mesmo após embates e desvios sofridos na idade adulta, se recorrerá como o locus unificador, garantia da identidade coerente pela qual responde a primeira pessoa do pacto autobiográfico. Assim, o lugar-comum "a criança é o pai do homem"1- e seus diversos sucedâneos proverbiais conduz o relato sobre a infância, fazendo desta um espaço de anunciação, prenúncio, em que se podem notar, de forma mais ou menos evidente, os sinais de excepcionalidade futura do autobiografado. Tudo já estava lá, parece dizer a narrativa: "Espinho que pinica, de pequeno já traz ponta".

Quando se trata das memórias de escritores consagrados, não de escritores nascidos apenas do fato da escrita, mas de um reconhecimento

${ }^{1}$ Trata-se, na verdade, de um verso de Wordsworth. 
público de sua atividade profissional que lhes garante um nicho na "república das letras", o principal sinal que a infância deve portar é o da futura trajetória literária do narrador-autor, não apenas signatário do texto mas também persona social.

Todo relato memorialísitico da infância de um escritor (persona social) traz, portanto, uma cena em que um texto literário ou um livro estabelecem a indissolúvel ligação dessa criança com um destino literário. A "cena da leitura" pode ser acompanhada ou combinada com uma "cena da escrita". Sylvia Molloy estuda esse aspecto das reminiscências de infância em Vale o escrito, dentro do contexto hispano-americano. Segundo Molloy, entre as várias formas que as referências a livros assumem na autobiografia, destacase a sua representação na infância como "cena primária textual". "O encontro do sujeito com o livro é crucial: o ato de ler é freqüentemente dramatizado, evocado em uma particular cena da infância que subitamente confere sentido a toda a vida." (p.33).

No espaço latino-americano, a leitura não funciona apenas como indício da futura carreira nas letras, mas também como índice da dependência cultural, lembrando a ascendência da cultura européia sobre o imaginário local. Malloy cita como exemplo a atração de Victoria Ocampo, quando criança, pelo Télémaque de Fénelon, comentando que "Não deixa de ser irônico que um livro escrito para a educação do Delfim de França despertasse tanto entusiasmo nas nurseries das repúblicas hispanoamericanas." (p.35).

O encontro com o livro na infância latino-americana é, assim, marcado pelo deslocamento, pela diferença, - o equívoco, quase - que imprime sobre esse encontro a marca das "idéias fora do lugar". A esse mal-estar Molloy atribui uma das atitudes freqüentes do escritor da América Latina frente ao livro: uma relação "carregada de desconforto, como no caso de Pablo Neruda" (...) "proclamando uma posição vitalista, anti-intelectual" (p.41). Marcado, no imaginário europeu, como "ser de natureza", a inserção do habitante do Novo Mundo na cultura será sentida como apropriação indébita. O escritor latino-americano se auto-representa, devido a esse desconforto, como um "saqueador do arquivo europeu" (p.41).

O livro como metonímia da literatura é constantemente o livro estrangeiro, traduzido ou não, objeto do desejo e da rapacidade do futuro escritor. Em certa medida, já se pode constatar desde sempre uma estrangeiridade em todo contato da criança com a leitura e a escrita, decorrente de sua pertinência ao mundo adulto, para o qual a criança ainda não dispõe de passaporte válido. Para estabelecer este ponto, tomo como 
objeto o relato ficcional-autobiográfico de Tolstói, Infância, que proponho como narrativa exemplar dessa fase da vida, pois ativa todos os elementos tradicionais do topos. No romance de Tolstói, os livros aparecem como propriedade privilegiada do adulto, que detém o saber e o administra homeopáticamente à criança. São livros áridos que, em lugar de atrair a criança por seu mistério, indicam precisamente o abismo entre a infância e a idade adulta.

É a cena da escrita que se mostra prenunciatória no romance. O protagonista, pré-adolescente, é arrancado do ambiente familiar protegido e lançado repentinamente na vida social, onde tem de se portar como um pequeno adulto. Nesse momento, vê-se na contingência de produzir um texto - um poema que será dado como presente de aniversário à avó, durante um festa da qual participam diversos nobres e dignitários da igreja. A produção do texto se mostra um combate improdutivo com as palavras, até que a criança resolve saquear o patrimônio do adulto - Nicolas apossa-se de um poema escrito por seu preceptor e, baseado nele, monta seu próprio poema. Este, porém, peca pela insinceridade: forçado pela necessidade de rimar, a criança expressa sentimentos que não condizem com a realidade. Pior ainda, sente que está traindo a mãe ao professar amor pela avó.

Aqui se esboçam, em rudimento, questões cruciais sobre o trabalho literário: a convencionalidade da linguagem, sua precária relação com a verdade, seu valor social, a cópia e a busca de uma originalidade impossível. Essa breve passagem enseja por si só toda uma reflexão sobre a literatura, mas no momento ela será tomada apenas como parâmetro para o exame de três livros de memórias brasileiros: Sob as ordens de mamãe, de Oswald de Andrade, Infância, de Graciliano Ramos, e Meus verdes anos, de José Lins do Rego.

No livro de Oswald, as lembranças da primeira viagem (à praia) misturam-se aos primeiros contatos com a literatura. A mãe menciona enfaticamente o tio escritor, colocando a profissão literária no horizonte do menino. Em seguida, o filho desse escritor [Inglês de Souza], préadolescente, comunica ao primo Oswald que está escrevendo "suas obras completas", a começar por um conto intitulado "O fantasma das praias". Oswald, depois da partida do primo para o Rio, apodera-se "sorrateiramente" do tema e título do outro, escrevendo ele próprio, aos onze anos, "O fantasma das praias". E o narrador adulto das memórias comenta: "É esse plágio o marco inicial de minha vida literária". O fato de a primeira viagem ao Guarujá e o encontro com o primo candidato a escritor não se ordenarem 
em seqüência cronológica é bastante eloqüente quanto à necessidade de Oswald ligar os dois fatos, aos quais associa também uma iniciação sexual "manquée". Interessante é ainda o uso da palavra "equívoco" com relação ao epíteto "literato", que adorna as menções ao tio Inglês de Souza: "Devo a um equívoco os benefícios oriundos de meu tio Herculano para a minha carreira literária. Sendo ele um literato, não soou mal essa palavra em casa, quando, muito cedo, eu me declarei também disposto a escrever". (p. 29)

É mais a exceção do que a regra esse explicitamento da conexão entre os episódios da infância e a futura carreira de escritor. O narrador das memórias deixa, em geral, ao leitor o trabalho de avaliar o lastro das cenas de leitura e escrita no desenvolvimento posterior do eu. Graciliano Ramos, em Infância, pontilha a narrativa com referências à relação diferenciada que se estabelece entre o menino e as palavras, sem, no entanto, deixar claro que essa relação serve de base ao tratamento da linguagem que mais tarde caracteriza seus romances. A conclusão se oferece com certa obviedade ao leitor, mas não é explicitada.

A primeira referência remonta aos primeiros anos de vida, quando, segundo a metáfora do autor, sua consciência ainda estava envolta em névoa, esperando que esta se dissipasse com a luz da manhã. Mesmo nebulosa, a memória do menino de três anos retém a cantilena do beabá ouvida por acaso durante uma viagem. A lembrança o marcará para sempre, com uma sentença de oráculo. Ainda no estágio das nuvens, ecoam reminiscências de estórias lidas e contadas pela mãe, não com o refinamento e as ressonâncias edípicas que Proust descreve na infância de Marcel, mas em um "matraquear capenga" de sertaneja semi-ignorante. O narrador, ao recordar, enfatiza a própria capacidade de remontar os cacos daqueles recontos toscos, que a mãe mais estropiava que conservava.

Antes ainda de aprender a ler, Graciliano era capaz de apreender o ritmo da redondilha popular em uma frase dita ao acaso: "Seu Ferreira de gibão, no cavalo de seu Afro" torna-se o dístico metrificado "Seu Ferreira de gibão/No cavalo de seu Afro". Aqui o narrador sugere a cegueira dos adultos com relação a seu dom: "Acabei por dividir a frase em dois versos, que a princípio declamei e depois cantei (...). Minha mãe se aborreceu, atirou-me os qualificativos ordinários. Estúpido, idiota." (p. 88)

No capítulo intitulado "Leitura", a criança é submetida à pior tortura de sua vida: aprender a ler pela cartilha. Depois de muita palmatória e lágrimas, consegue soletrar uma frase enigmática: "Fala pouco e bem: terte-ão por alguém". Consulta esperançoso a irmã mais velha: "Mocinha, quem 
é Terteão?", sem obter resposta satisfatória. Se levarmos em conta que a irmã, em seu turno, também estudara na mesma cartilha, sem se deixar atrair pela palavra desconhecida, teremos que concluir, em concordância tácita com o narrador, que a pergunta era um indício da natureza especialmente curiosa e original daquela criança.

A interferência da escola no idílio entre o menino Graciliano e as palavras é desastrosa. Ele suspeitava de um complô montado pelo pai, a mestra e a matéria impressa. Nas várias cenas dedicadas à leitura escolar fica, por oposição, estabelecida a cultura oral, embora fragmentária e deturpada, como a única que de fato favorece o progresso do espírito da criança: "Na verdade, os melhores [mestres] que tive foram indivíduos ignorantes. Graças a eles, complicações eruditas enfraqueceram, traduziram-se em calão" (p. 123). O livro referencial na narrativa de Infância é o compêndio do Barão de Macaúbas [Abílio César Borges], conhecido como terceiro livro de leitura. Embora o autor tenha ficado conhecido como grande pedagogo e reformador do ensino no Brasil, trabalho a que se deve seu título de nobreza, outorgado por Pedro II, Graciliano sente imediata antipatia pelo volume, que considera feio ["Um grosso volume escuro, cartonagem severa. Nas folhas delgadas, incontáveis, as letras fervilhavam, miúdas, e as ilustrações avultavam num papel brilhante como rasto de lesma ou catarro seco." (p. 12)], tomando como metonímia do conteúdo o retrato "barbudo e antipático" do Barão no frontispício. As histórias, apólogos didáticos em que os diversos animais são dotados de fala, soam extremamente artificiais e até perversas para o menino, que se indigna por lhe fazerem perder tempo com coisas absurdas. A leitura, que não faz sentido para ele, acaba por lembrarlhe "o enigma apresentado no catecismo. - Podemos entender bem isso?/ - Não, é um mistério.” (p. 131).

Em Meus verdes anos, de José Lins do Rego, temos um relato bastante semelhante no que toca ao aprendizado das primeiras letras. Apesar de não sofrer tantos castigos físicos quanto o protagonista de Infância, Dedé, o avatar infantil do escritor pernambucano, experimenta como tortura mental e moral sua entrada no mundo da leitura. Arrancado da costumeira observação direta do ambiente que o cerca, o menino não consegue alcançar o estatuto de representação da linguagem escrita. O domínio do alfabeto lhe é proposto como rito de passagem, sem qualquer recompensa em termos de uma maior compreensão do mundo ou de alimento para o espírito. Depois de muito penar, a conquista da leitura só parece ter uma aplicação: mostrar às visitas que Dedé já pode soletrar as manchetes dos jornais que lhe são mostradas 
com esse exclusivo fim. A partir desse ponto, até o fim do livro, nenhum texto escrito é mencionado. Não se tem sequer notícia de que o menino tenha prosseguido os estudos. O colégio interno permanece, no entanto, como uma ameaça pendente e progressivamente próxima.

Contrastando com as infâncias nordestinas, as memórias de Oswald de Andrade não mostram uma entrada tão conflituosa no universo da palavra impressa. O pequeno Oswald parece simplesmente passar incógnito pela prova da alfabetização:

Não sei dizer como me alfabetizei. Sei que tive um professor de desenho que nada me ensinou.

Dos livros que conheci na mais afastada infância, lembro-me de "As Espumas Flutuantes" de Castro Alves, que meu pai me deu. Não entendi nada mas gostei. (p. 59)

Não mostrando propriamente uma aversão pela leitura, Oswald ainda assim toma distância dos textos "prontos", que menciona com nonchalance e até um leve desprezo, dando muito mais ênfase à própria produção literária, que se inicia como pendor, inclinação natural, antes que o futuro poeta tenha algo para dizer: "Nas noites quietas, meus pais deitavam-se cedo. Eu procurava, sentado à mesa de jantar, ensaiar num caderno a minha nascente literatura sem motivos." (p. 49).

A desconfiança ou descaso com o livro associa-se, nesses memorialistas brasileiros, à rejeição à escola, indicando uma crítica à literatura como instituição. A criança assume, nesse cenário, a roupagem simbólica do inventor, do inaugurador do mundo, a partir do qual tudo pode começar de novo. Não como tabula rasa em que se inscreve a lei, mas como aquele que, ignorando o que o antecedeu, passa a escrever-se a si próprio. A imagem casa muito bem com a profissão de fé modernista, em sua busca pelo novo, principalmente no caso de Oswald de Andrade. Em Graciliano Ramos, que escreveu Infância em seu período comunista, pode-se identificar a criança ao "homem novo" que nascerá com a revolução, em total ruptura com o passado. (Ainda mais se levarmos em conta as numerosas semelhanças entre as memórias de Graciliano e as de Máximo Górki, escritor da Rússia comunista). Já em José Lins do Rego, prevalece a idéia rousseauniana da criança como ser natural, cuja inocência e frescor contrastam com o entorno corrompido. A sugestão é que o escritor deve ter como fonte esse primeiro estágio da consciência, em que as coisas se dão a conhecer sem a mediação de textos e formulações prévias. 
Interessante, no predomínio da cena da escrita sobre a cena da leitura que detectamos nas memórias citadas, é a flagrante diferença entre os escritores brasileiros e os hispano-americanos de que trata Sylvia Molloy. Mesmo sem recorrer ao estudo de Molloy, basta lembrar a fascinação do livro e da biblioteca em Borges para que essa diferença se faça presente. "Reler e reescrever o livro europeu" (Molloy, p. 31) é um empreendimento reincidente do escritor hispano-americano - Pierre Menard "criollo" - que se constitui, segundo Molloy, em experiência "selvagem e inquietante". Creio que se pode encontrar na Cidade letrada de Ángel Rama um esclarecimento pelo menos parcial dessa atração fatal. Sylvia Molloy a denomina "postura" - e quase "pose".

Se os brasileiros preferem imaginar a cena da escrita como anterior e superior à da leitura, isso se deverá, talvez, à política de terra arrasada, em todos os sentidos, que presidiu à colonização, ocupação e delimitação do Brasil, país em que a cultura tem de sobreviver, como os arbustos do cerrados, às queimadas sucessivas, brotando sempre de novo em formas orais e nômades. Aqui a literatura impressa não nasceu de uma efervescência cultural, mas como atitude, postura, pose, artificialmente armada, resultando muitas vezes engessada e anêmica.

Pose é, entretanto, também a atitude de negação dos nossos memorialistas com relação ao livro. Graciliano Ramos, em sua detração do livro, está, contudo, se servindo das memórias de Máximo Górki como livroguia. ${ }^{2}$ José Lins do Rego, que descreve a infância sem livros do futuro escritor, parece, no entanto, precisar prefigurá-la como livro - no romance Menino de engenho (e a analogia entre romance e livro está bem estabelecida, vejase Autobibliografias, de Abel Barros Baptista). Quanto a Oswald de Andrade, que se retrata como menino experimental que escreve antes de ter lido, a certa altura desiste, em Sob as ordens de mamãe, de escrever um texto inédito e passa a simplesmente copiar trechos de seu diário de garçonnière "O perfeito cozinheiro das almas deste mundo", que já é, ele próprio, uma prova da necessidade de fazer da vida o livro e do livro a vida.

Não há propriamente uma contradição entre a ideação da vida em livro e a rejeição do livro na vida que as memórias desses escritores demonstram. O que há é um distanciamento entre o livro ideal ou livro ideado e o livro real - digamos melhor, entre o livro escrito (ou por escrever)

\footnotetext{
${ }^{2}$ Não tenho comprovação documental dessa influência, mas ela me parece perfeitamente plausível devido às simpatias políticas de Graciliano.
} 
e o livro lido. Máximo Górki, em Ganhando meu pão, conta o fascínio do adolescente pela leitura, os estratagemas a que recorre e castigos que tem de suportar na sua busca pelo livro. Entretanto, mal se iniciara aquele leitor no mundo da literatura, seu incipiente espírito crítico já o faz rejeitar noventa por cento das brochuras que lhe chegam às mãos como meras enganações. Dir-se-ia que é a rejeição do que lê que impulsiona o futuro autor à escrita. Do mesmo modo, é o caráter tedioso e de todos os modos alheio dos livros da nursery que fazem nascer no pequeno Nicolas, se o tomarmos como uma figuração da infância do autor, os primeiros traços do grande Tolstói. ${ }^{3}$ Como contraprova, pode-se construir o argumento de que a profusão de bons e atraentes livros manterá o futuro intelectual por eles seduzido na infância sempre na posição de leitor. Assim é que Borges se verá, mesmo ao escrever, sempre como um re-fazedor, um re- ou des- leitor.

Investigar mais profundamente essas peculiaridades do memorialismo brasileiro e latino-americano e seus traços comuns com outras literaturas é tarefa a demandar um demorado esforço investigativo, uma tarefa comum para os diversos estudiosos que se dedicam ao tema em diversas instituições do continente. Ficam, portanto os comentários como instigação ao prosseguimento da pesquisa.

\section{Referências Bibliográficas}

ANDRADE, Oswald de. Um homem sem profissão. Rio de Janeiro: José Olympio, 1954.

GÓRKI, Máximo. Ganhando meu pão. Trad. Boris Schnaiderman. São Paulo: Brasiliense, 1986.

MOLLOY, Sylvia. Vale o escrito. A escrita autobiográfica na América bispânica. Trad.Antônio Carlos Santos. Chapecó: Argos, 2003.

RAMOS, Graciliano. Infância. Rio de Janeiro: Record, 2003.

REGO, José Lins do. Meus verdes anos. Rio de Janeiro: José Olympio, 1956.

TÓLSTOI, L. Infância. Porto: Livraria Civilização Editora, 1955.

\footnotetext{
${ }^{3}$ Ressalte aqui, novamente, que Infância de Tolstói é um livro de ficção. Trata-se apenas de inventariar as representações do livro e da escrita na escrita de Tolstói.
} 


\section{Resumo}

Em suas memórias de infância, os escritores quase sempre inserem uma ou mais cenas contendo sinais, freqüentemente em forma de um livro específico, que pressagiariam sua futura carreira literária, muitas vezes em contraste com um cenário de grande pobreza material e intelectual, ou de discriminação e desvalorização da criança. Esse recurso chega a constituir quase um topos na escrita memorialística e foi estudado por Sylvia Molloy, no memorialismo latino-americano, sob a denominação de "a cena da leitura". Textos tão distantes quanto os de Tolstói e Oswald de Andrade podem ser explorados desse ponto de vista, suscitando questões sobre filiação intelectual.

\section{Abstract}

In their memoirs of childhood, writers often insert one or more scenes that bring out pressages, generally under the sign of a specific book, of their future literary career, frequently against a background of great material and intelectual want, in which the child is overlooked and discriminated. This resource can be said to constitute a topos in the genre and has been investigated by Sylvia Molloy concerning Latin American autobiographic writing, under the concept of "the scene of reading". Authors as far apart as Oswald de Andrade and Tolstoi can be examined from this perspective, giving rise to reflections on intelectual affiliation. 